\title{
Geotechnical Investigations and Proposal for Stabilization and Recovery Slope on Highway BR-010 Stretch in Aparecida do Rio Negro to Goiatins, Tocantins, Brazil
}

\author{
Rideci Farias ${ }^{1}$, Haroldo Paranhos ${ }^{1}$, Jovino Rachid Araújo ${ }^{2}$, \\ Leonardo Ramalho Sales ${ }^{3}$, and Roberto Pimentel ${ }^{4(\square)}$ \\ ${ }^{1}$ UCB, Reforsolo Engenharia, UniCEUB, IesPlan, Brasília, Brazil \\ rideci.reforsolo@gmail.com, reforsolo@gmail.com \\ ${ }^{2}$ CMT Engehharia, Brasília, Brazil \\ jovino@cmtengenharia.com.br \\ ${ }^{3}$ UniCEUB, Brasília, Brazil \\ leonardoramalhosales@gmail.com \\ ${ }^{4}$ UnB, Brasília, Brazil \\ eng.robertopimentel@gmail.com
}

\begin{abstract}
This article presents the results of geotechnical studies and proposals to stabilize embankments referring to cuts $16,23,25,30$ and 31 of the BR-010 referring to Aparecida do Rio Negro a Goiatins, State of Tocantins. The study consisted in the execution of a field incursions program for verification of geotechnical conditions along the indicated stretch, running lab tests, and stability analysis of embankments in order to indicate solutions to cuts made necessary for the completion of the highway. In terms of characterization of the problem, it presents part of the photographic survey conducted in November 2007 with the conditions of the most critical slopes. There is in the pictures that the side slopes to the highway were in the process of degradation and (or) progressive destabilization requiring urgent interventions aimed at mitigating the ongoing problems. In terms of geometry, the slope had heights up to approximately $35 \mathrm{~m}$. To determine the parameters necessary to verify the stability of embankments using three undeformed blocks corresponding soil to cuts 25 and 31. Samples of identifications are presented and the summary of the results of geotechnical tests performed and certain parameters. In laboratory tests, it was found that the strength parameters (cohesion and angle of friction) diverged somewhat from the usual laboratory parameters obtained in soils. This behavior was due to the fact that the heterogeneity of the samples for the presence mainly of discontinuities in the collected blocks. Before the run stability analysis and field surveys, it was found, the need for actions aimed at solving problems for marginal slope to the highway. Thus, due to the proximity of the intense rainy season, it was proposed the reconstruction of slope with surface protection of them aimed at stabilization and protection against erosion, as well as the execution of superficial and deep drainage. Aiming to further
\end{abstract}

The original version of this chapter was revised: Incorrect author name has been corrected. The erratum to this chapter is available at https://doi.org/10.1007/978-3-319-61902-6_33 
verify the possible degradation of the slopes by rain, was sought in INMET's website (National Institute of Meteorology) precipitation to the region. It was found that for the time in January, February and March rainfall is considerably high, which could further compromise the integrity of the executed cuts. Faced with this possibility, he indicated consider the emergency actions that could prevent this degradation. Actions such as the reduction and protection of embankments shown in the study.

\section{Introduction}

This article presents the results of geotechnical studies and proposals to stabilize embankments referring to cuts 16, 23, 25, 30 and 31 of the BR-010 referring to the Black River Aparecida excerpt Goiatins, State of Tocantins, made in the year 2007. The study consisted in the execution of a field incursions program for verification of geotechnical conditions along the indicated section, as well as the execution of laboratory tests, and stability analysis of embankments in order to indicate the solutions made cuts necessary to completion of the highway.

\section{Problem Characteristics}

In terms of characterization of the problem proceeded to the assessment and field analysis accompanied by an extensive survey photographic held in November 2007 with the conditions of the slopes 16, 23, 25, 30 and 31. It can be seen in Figs. 1, 2, 3, 4, $5,6,7,8,9,10,11,12$ and 13 which the side slope to the highway, in some cases, were in the process of degradation and (or) progressive destabilization requiring urgent interventions aimed at mitigating the ongoing problems. In terms of geometry, the slope presented heights up to about $35 \mathrm{~m}$, as evidenced in the analyzed sections and shown in this article.

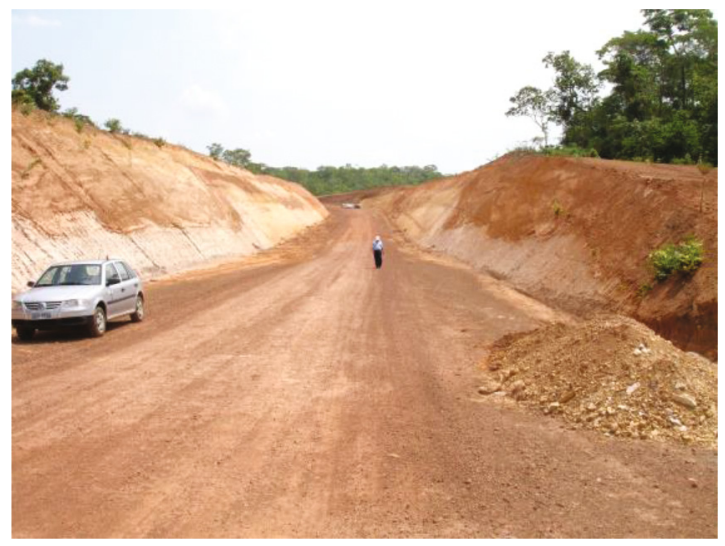

Fig. 1. General view of part of slope 16 . 


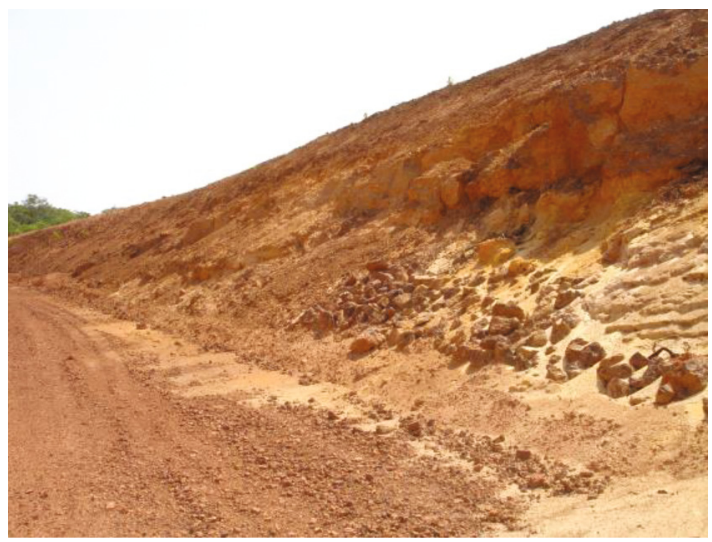

Fig. 2. General view of part of cut 16 with superficial erosion.

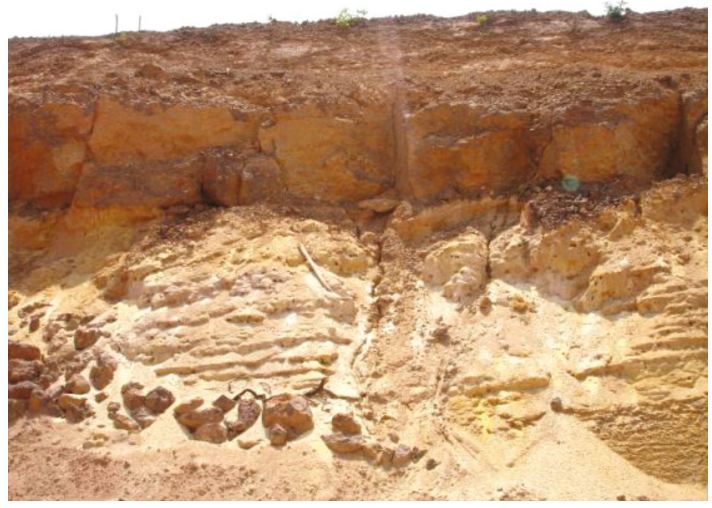

Fig. 3. General view of part of the cut 16 with superficial erosion.

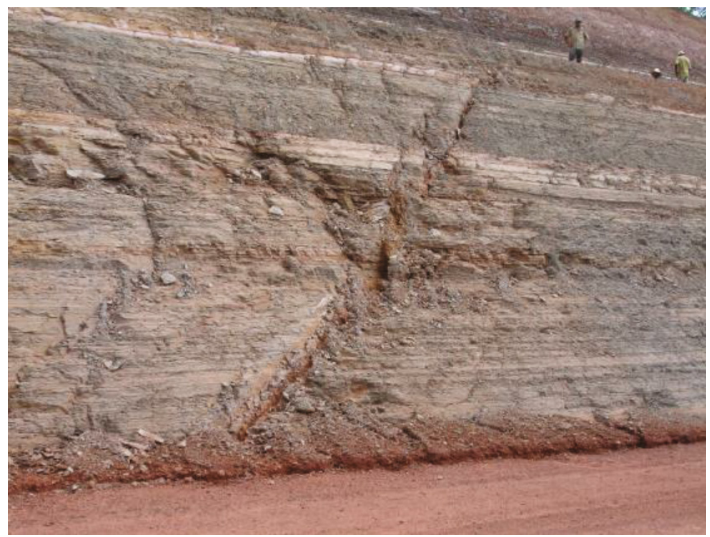

Fig. 4. View of the slope of cut 23. 


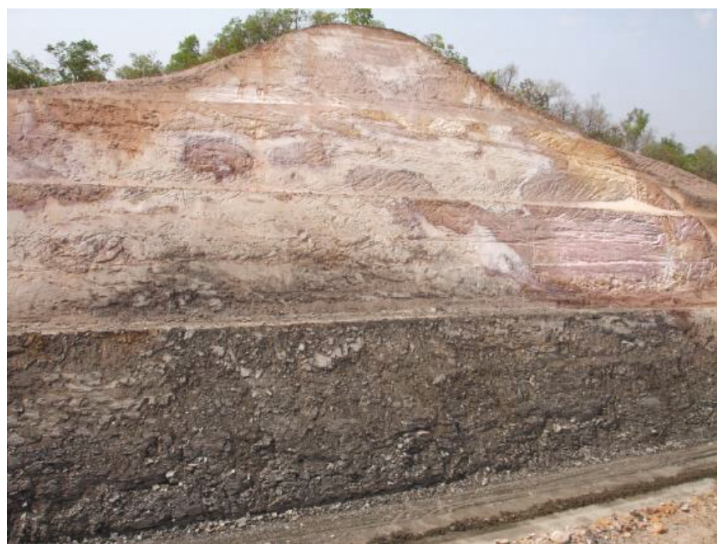

Fig. 5. Cut 25, still intact (September 2007).

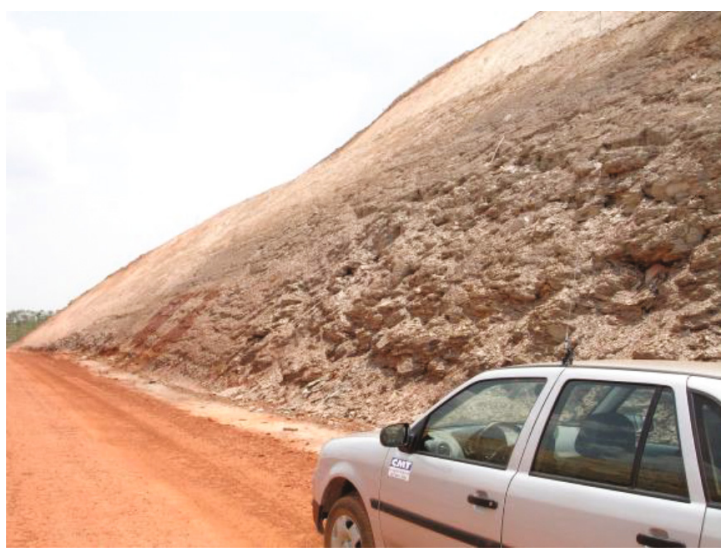

Fig. 6. Slope of cut 25 starting degradation process of slope.

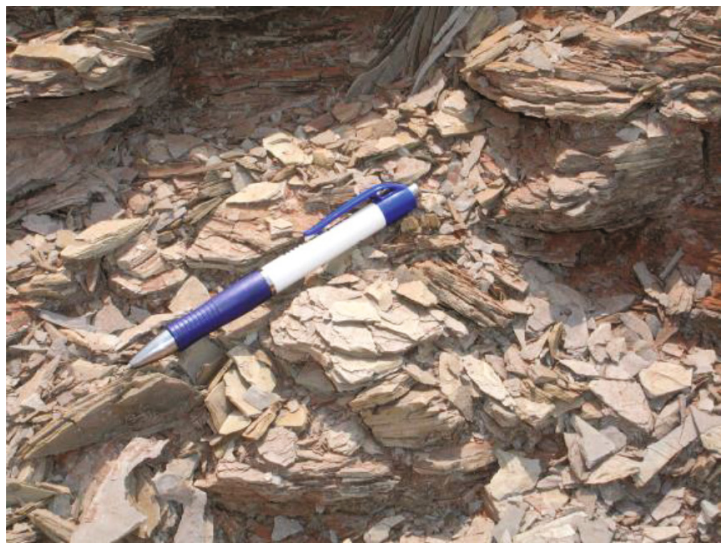

Fig. 7. Material of lower horizon of cut 25. 


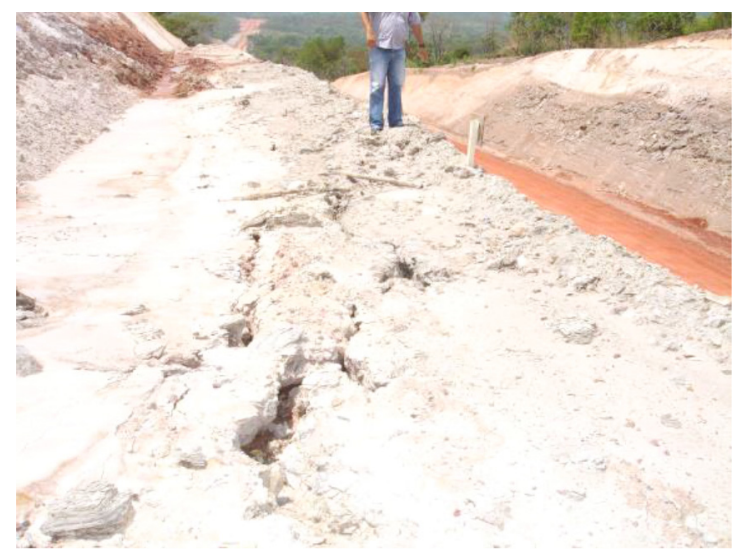

Fig. 8. Traction cracks in the berm slope of cut 25 .

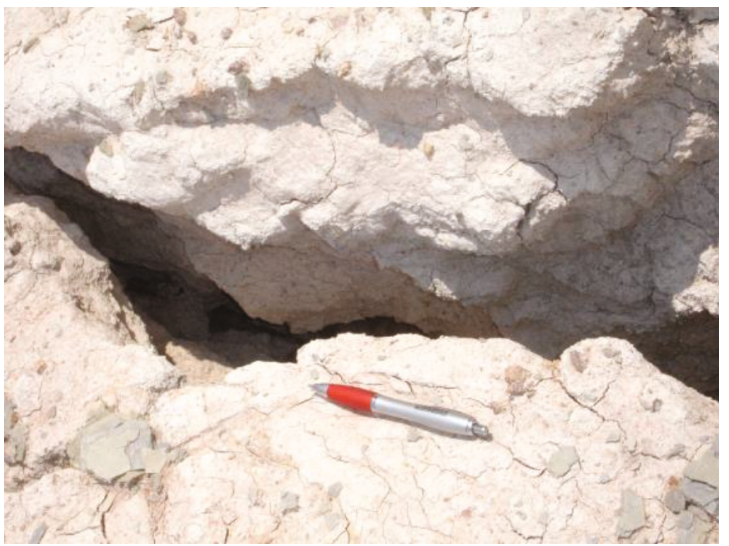

Fig. 9. Traction cracks on berm slope of cut 25 .

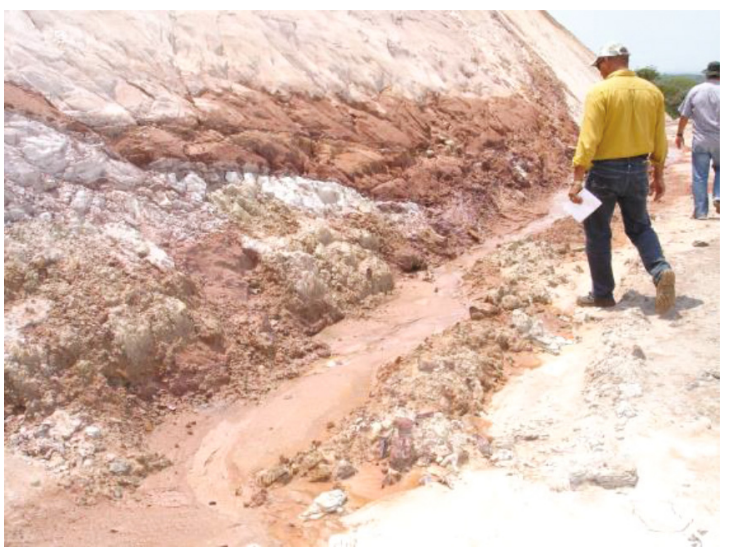

Fig. 10. Saturation from the slope basis in cut 25 . 


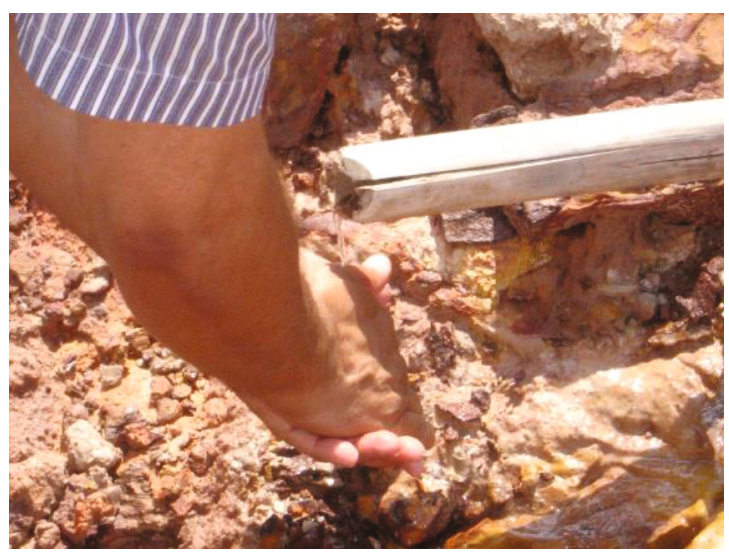

Fig. 11. Upwelling water in cut 25 slope.

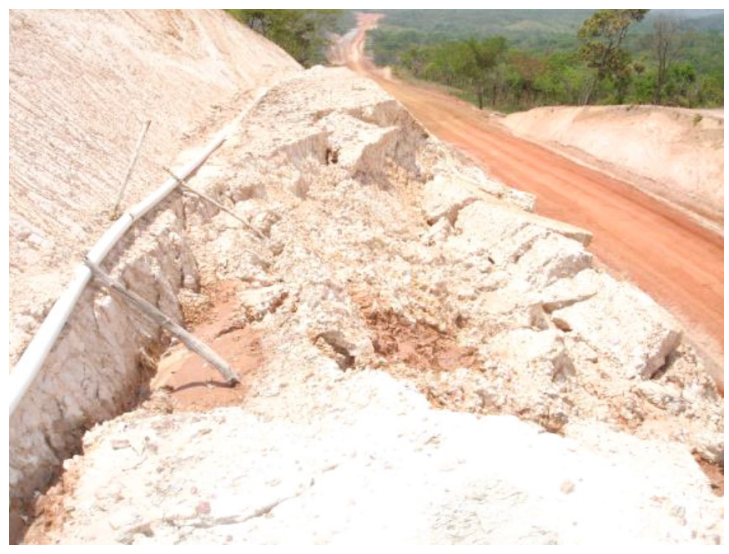

Fig. 12. Failure stretch in cut 25 slope.

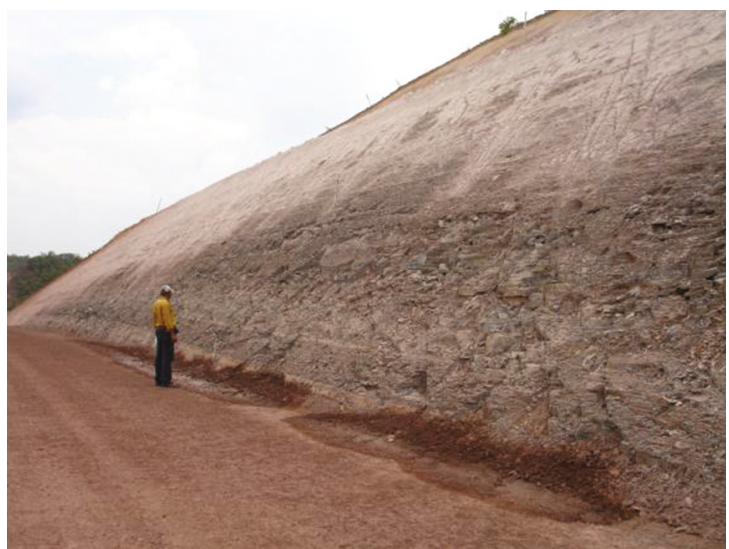

Fig. 13. Cut 31 (slope basis saturation). 


\section{Geotechnical Testes Performed}

To determine the parameters necessary to verify the stability of slopes, we used three undisturbed samples of soil corresponding to Sections 25 and 31. Table 1 shows the sample to the Court 25, but also the summary of the results of the conducted geotechnical testing and certain parameters. The three undisturbed soil samples were used for executing the natural moisture of assays, bulk density and direct shear to define the strength parameters. The tests were performed in accordance with relevant standards and (or) the usual procedures used in geotechnical laboratory. For direct shear tests (ASTM D3080/D3080M: 2011), the bodies of the test piece were tested in the flooded condition in order to verify possible critical mechanical behavior of soil.

Table 1. Summary of geotechnical tests realized and determined parameters for sample of cut 25 .

\begin{tabular}{l|l|l}
\hline \multicolumn{3}{l}{ CUT 25 - Stake 1410 (slope right side) - Level 310,394 m } \\
\hline Specific weight natural & $\gamma_{\text {nat }}\left(\mathrm{kN} / \mathrm{m}^{3}\right)$ & 22,17 \\
\hline Natural humidity & $\mathrm{w}(\%)$ & 9,38 \\
\hline Effective cohesion (Top) & $\mathrm{C}^{\prime}(\mathrm{kPa})$ & 78 (Condição Inundada) \\
\hline Effective angle of friction (Pico) & $\phi^{\prime}$ (graus) & 19 (Condição Inundada) \\
\hline Effective cohesion (Residual) & $\mathrm{C}(\mathrm{kPa})$ & 27 (Condição Inundada) \\
\hline Effective friction angle (Residual) & $\phi^{\prime}(\mathrm{graus})$ & 15 (Condição Inundada) \\
\hline Specific gravity apparent dry $\left(\mathrm{kN} / \mathrm{m}^{3}\right)$ & $\gamma_{\mathrm{d}}\left(\mathrm{kN} / \mathrm{m}^{3}\right)$ & 20,27 \\
\hline Specific weight of solids (or grains) & $\gamma_{\mathrm{s}}\left(\mathrm{g} / \mathrm{cm}^{3}\right)$ & 2,81 \\
\hline Specific weight saturated $\left(\mathrm{kN} / \mathrm{m}^{3}\right)$ & $\gamma_{\mathrm{sat}}\left(\mathrm{kN} / \mathrm{m}^{3}\right)$ & 22,86 \\
\hline Void index & - & 0,36 \\
\hline Porosity & $\mathrm{n}(\%)$ & 26,43 \\
\hline Saturation level $(\%)$ & $\mathrm{Sr}(\%)$ & 73,38 \\
\hline
\end{tabular}

\section{Comments About Soil Samples Collected}

It appears from Table 1, the example of other tests performed for other samples not shown in this article, the strength parameters (cohesion and friction angle) diverge somewhat from the usual parameters obtained for laboratory soil. This behavior was due to the fact that the heterogeneity of the sample by the presence mainly of discontinuities in the collected blocks.

Such discontinuities were also found in the field when the three surveys conducted in the months of September, November and December 2007, to evaluate the cuts run along the highway.

These discontinuities contributed directly to the technical difficulties encountered by the Geotechnical Laboratory when the molding of the samples for the appropriate tests. Such difficulties caused repetitions of several tests in which there was no convergence results. 


\section{Slope Stability Analysis Performed}

Due to the difficulties, both in the collection of the blocks as the molding of the test bodies, obtaining a few parameters for ordinary soils of the North Central region of Brazil, it was performed several analyzes of stability of embankments through computer program SLOPE/W, version 2007, marketed by Geo-slope International. These analyzes understood the use of the parameters obtained in the laboratory, as well as simulations with more realistic parameters that represented stability with safety factor close to 1 (one) to the slope of the Court 25, in compliance with consistent conditions of embankments.

After several tests in order to find more realistic parameters for soil that made up the slopes of the cuts 25 and 31, corrected to the upper and lower horizon soil obtaining the values shown in Tables 2 and 3 (horizon) and 6 (lower horizon).

Table 2. Strength parameters fixed for upper horizont soil.

\begin{tabular}{|c|c|c|}
\hline \multicolumn{3}{|c|}{$\begin{array}{l}\text { Parametrosde Resistencia para o } \\
\text { Horizonte Superior }\end{array}$} \\
\hline Coesão Efetiva & $\mathrm{C}(\mathrm{kPa})$ & 14 \\
\hline Ângulo de atrito efetivo & $\phi^{\prime}$ (graus) & 26 \\
\hline
\end{tabular}

Table 3. Strength parameters fixed for below horizont of soil.

Parametros de Resistencia para o

Horizonte Superior

\begin{tabular}{l|l|l}
\hline Coesão Efetiva & $\mathrm{C}(\mathrm{kPa})$ & 44 \\
\hline Ângulo de atrito efetivo & $\phi^{\prime}$ (graus) & 26 \\
\hline
\end{tabular}

For the cohesion values, remained the value of $14 \mathrm{kPa}$ found for the upper horizon, and it is a high cohesion value for characteristic soils of the region, decreased to $78 \mathrm{kPa}$ to $44 \mathrm{kPa}$ related to the lower horizon. The value of $44 \mathrm{kPa}$ due to the fact that several stability analyzes with a view to the compatibility of what was happening on the field. It is surprising that value because the soil had low cohesion when desconfinado, but when confined cohesion tended to be higher. For the case in question on which the slope face exposure the soil tended to expand with the consequent breakdown necessitating thus of at least surface protection of the slope.

It should be noted that the field located various types of breaks were observed, highlighting the planar, circular and small spalling. Within this complexity, it broke up in most cases the reproduction of circular breaks that are quite common in soils. Simplification adopted in part of the study to circulate break comes the already mentioned complexity in terms of heterogeneity and the difficulties encountered, both in the selection of collecting the material and the molding of the samples in order to obtain parameters that could represent the field of similarity. Within the subject matter, for the 
analysis and conclusions as to the positioning in the appropriate interventions, aiming stable geometries, one should consider - in addition to computational studies with different characteristics, but also the importance of surveys in situ by professionals who are able to position solutions address the various problems that may be identified.

In terms of stability analyzes were done for several cuts 16, 23, 25, 30 and 31 represent, in general, we found the slopes along the portions studied. Below, we present the studies to the slope of the cut 25 because it is one of the most critical checked in the field. Initially shows the stabilities of the cut 25 for the parameters obtained in the

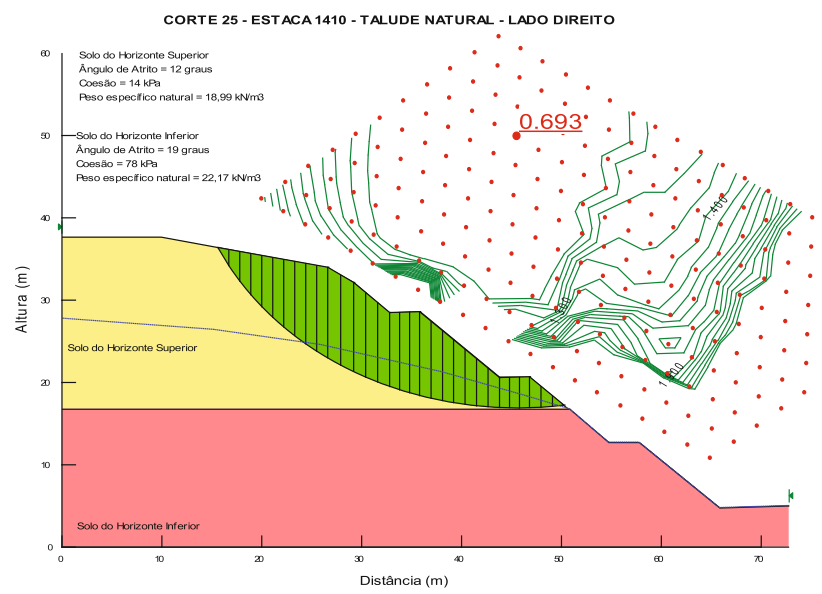

Fig. 14. Cutting 25 stability with lab parameters $(F S=0.693)$ - Stake 1410 (natural slope right side).

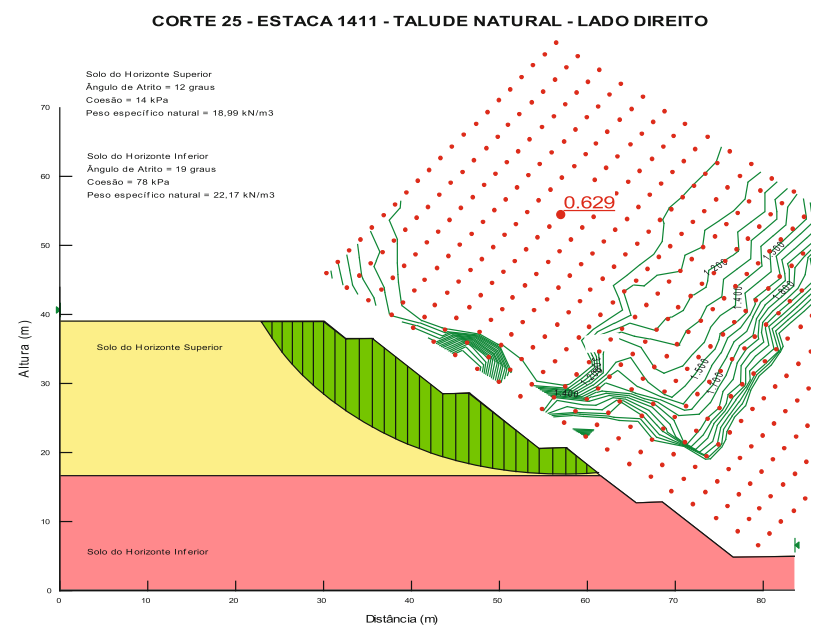

Fig. 15. Cutting 25 stability with lab parameters $(F S=0.629)$ - Stake 1411 (natural slope right side). 
laboratory just to check, since the obtaining of strength parameters has been compromised, as mentioned above. Subsequently, we present the analysis with more realistic parameters in compliance with those found soils and conditions prevailing in the field.

\subsection{Stability with Parameters Obtained in Lab}

Next, in Figs. 14 and 15, the stability analyzes are presented, with the strength parameters obtained in our laboratory for the cuts 25 on cuttings 1410 and 1411 .

\section{Considerations About Performed Slope Stability Analysis}

Before the run stability analysis and field surveys, there was the need for actions aimed at solving the problems that the marginal slope to the highway had presented. For this, it was indicated two types of interventions following:

(a) The first type of proposed intervention was the reduction (retaludamento) of slopes to stable geometries within the engineering practice, considering the economy, environment, insertion area of the enterprise, in other factors. In this case, it recommended to check the availability of areas to cut beyond the highway right of way, if necessary, and place of disposal of material removed;

(b) The second type of intervention was the recommendation for adoption of structures that allowed the stabilization of the now existing embankments. Within this practice there are several solutions such as soil nailing, bolting, root cuttings, etc.

For the case in question, due to the proximity to the most intense rainy season, there was the need to intervene as soon as possible. Within the time that was available, then recommended him retaludamento sections with the execution of deep drainage and surface. For deep drainage usually use the DHP - Drain subhorizontal Deep and surface drainage is commonly contemplated by the vestment of drains and channels.

For simulations of retaludamento proceeded to several stability analysis in the studied slope. By way of example, is presented in Figs. 16 and 17 the analysis of stability for the cut 25 in the most critical Cutting (Cutting 1411). For these simulations, broke up the natural sections with the execution of cuts for defining stable geometries within the practice of engineering. After several simulations came to embankments with $1 \mathrm{~V}: 1.5 \mathrm{H}$ for the cuts $16,23,30$ and 31 . This primarily by the need to install any type of surface protection on the slopes, as an example geocell in order to prevent erosive processes.

For cutting 25, broke up the natural slope safety factor equal to 1.007 (Fig. 16), with the implementation of retaludamento and introducing deep subhorizontal drains to relegation in N.A. within the massif.

Initially, simulated an approximate cross-sectional area of $358 \mathrm{~m}^{2}$ Stake 1411. In this situation, there was a need to move laterally out of the situation of the road counting from the bottom up - the first edge in $5 \mathrm{~m}$, second at $10 \mathrm{~m}$, the third in $15 \mathrm{~m}$, the fourth at $18.5 \mathrm{~m}$ and fifth in $20 \mathrm{~m}$. Figure 17 shows such a situation where we got the 1,118 Safety factor that represents a low value for the stability of the slope in question. 


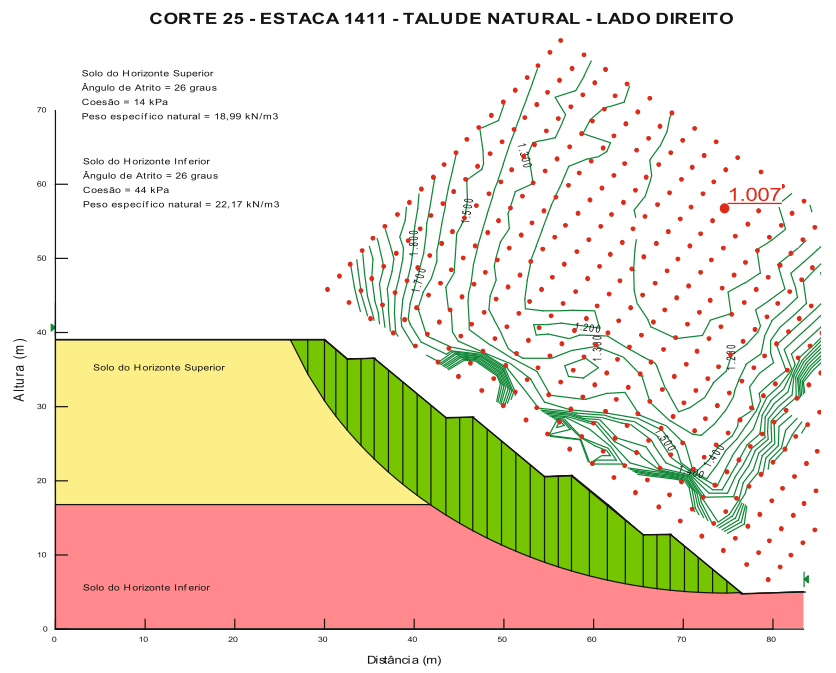

Fig. 16. Cutting 25 Stability with fixed parameters - Estaca 1411 (natural slope - right side).

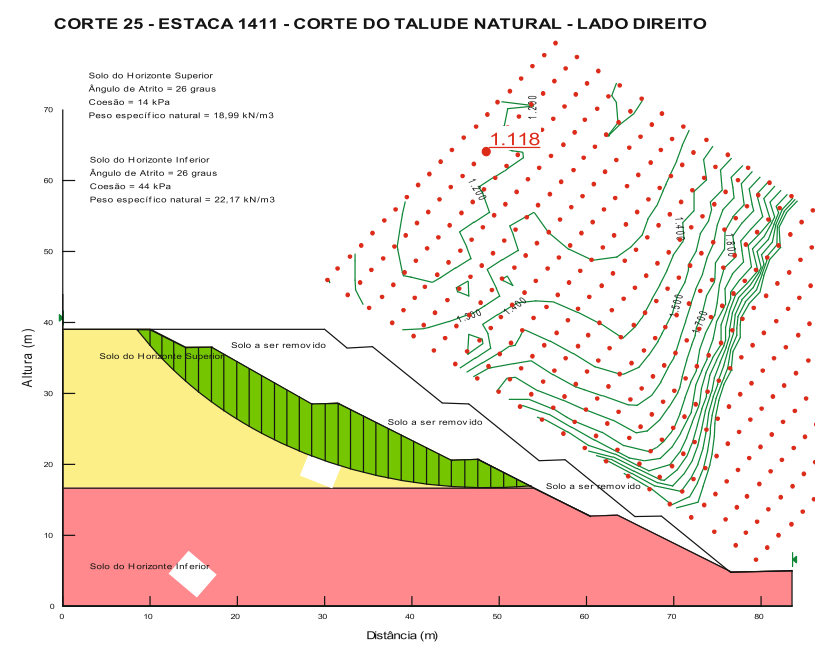

Fig. 17. Cutting 25 stability with proposal remotion of soil - Stake 1411 (natural slope - right side).

In addition to retaludamento, simulated to the lowering of N.A. inside slope which represents the introduction of the sub horizontal drains for the removal of excess water. In this situation it obtained the Safety Factor of 1.488 , considered satisfactory for the type of work in question. Figure 18 shows the situation analyzed. 


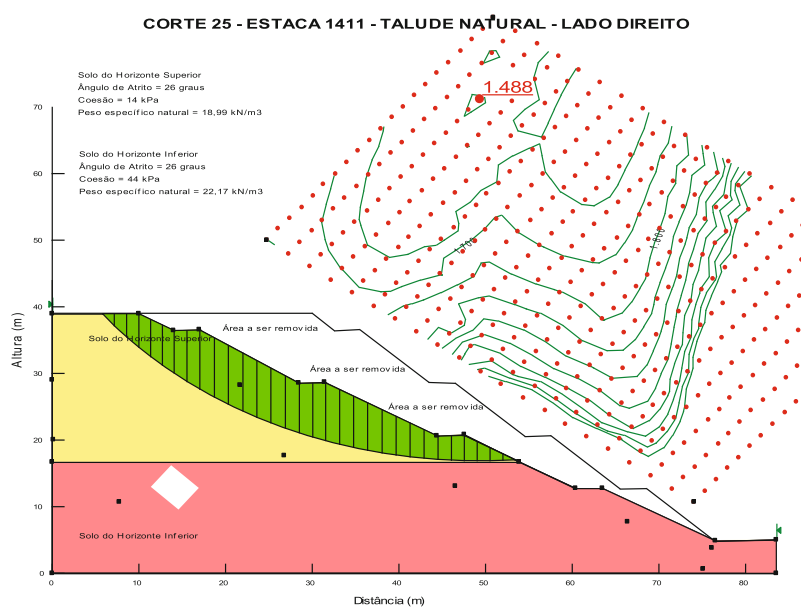

Fig. 18. Cutting 25 Stability - Stake 1411 (natural slopes - right side) - Low NA (introdution of deep subhorizontal drain).

\section{Recommendations for Stabilization and Recovery of the Studied Slopes}

Before the run stability analysis and field surveys, it was found, as already mentioned, the need for actions aimed at solving the problems that the marginal slope to the highway had presented. Thus, due to the proximity of the intense rainy season approaching, it proposes the retaludamento Slashes 16, 23, 25, 30 and 31, with surface protection of slopes aimed at stabilization and protection against erosion that occurred and came to occur, as well as the execution of superficial and deep drainage.

Another recommendation made was the draining mattress running on the highway over the cuts implemented in order to prevent possible upwelling of water that could compromise the surface layers of the highway, as the sub-base, base and coating, that the saturation finding the bases of slopes in the run cuts.

\section{Pluviometric Analysis of the Area}

In order to verify the possible degradation of the slopes by rain, was sought in INMET's website (National Institute of Meteorology) precipitation for the region in previous years, and the period of the executed cuts. It was found in Figs. 19, 20, 21, 22, 23 and 24 in the months of January, February and March there is heavy rainfall, which could further compromise the integrity of the executed cuts. Faced with this possibility, it had to consider the urgency of actions that could prevent degradation. Actions such as the reduction and protection of embankments listed in this article and the complete work developed. 


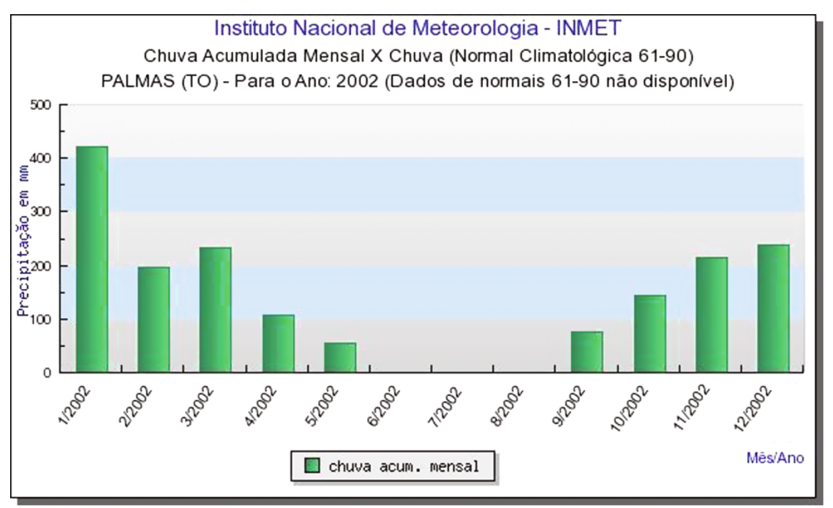

Fig. 19. Accumulated rainfall of 2002.

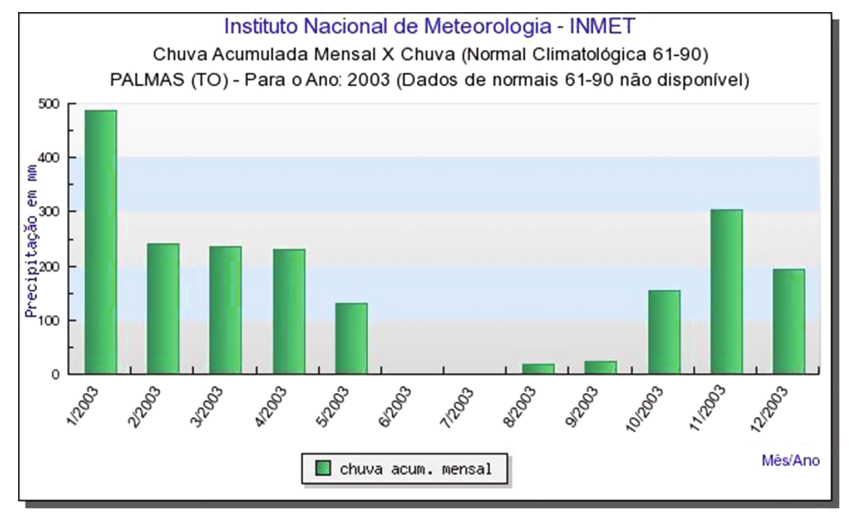

Fig. 20. Accumulated rainfall of 2003.

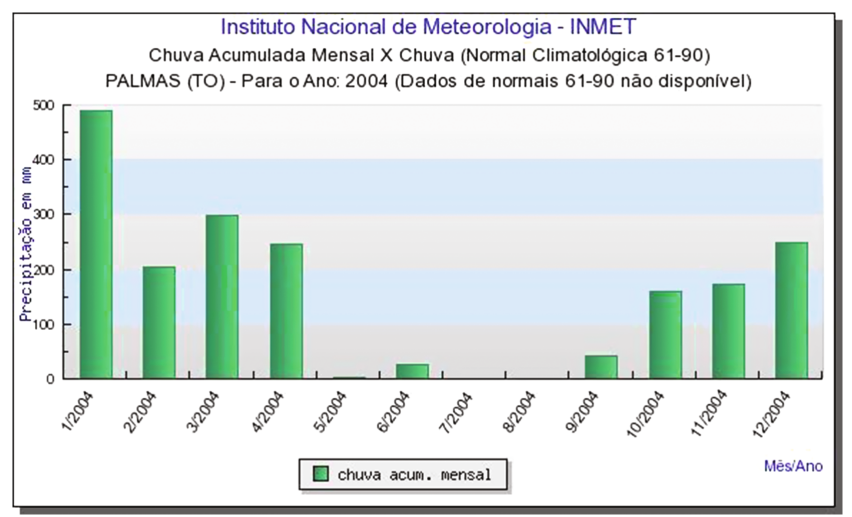

Fig. 21. Accumulated rainfall of 2004. 


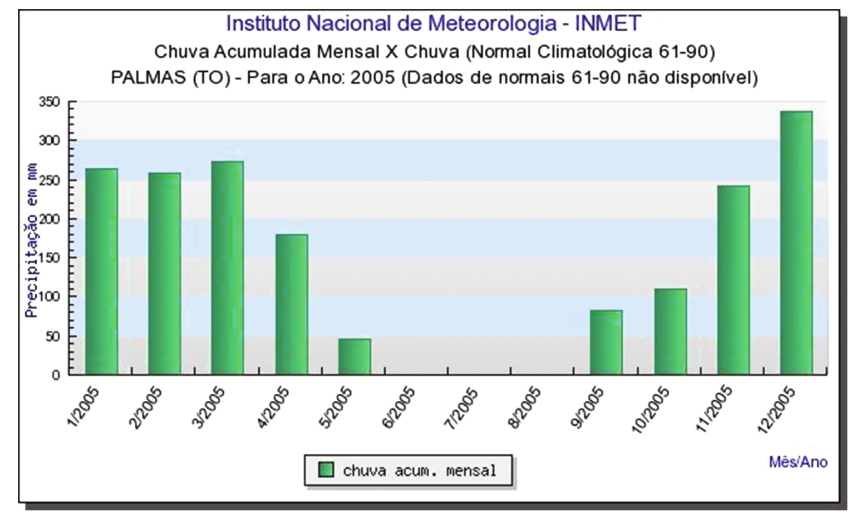

Fig. 22. Accumulated rainfall of 2005 .

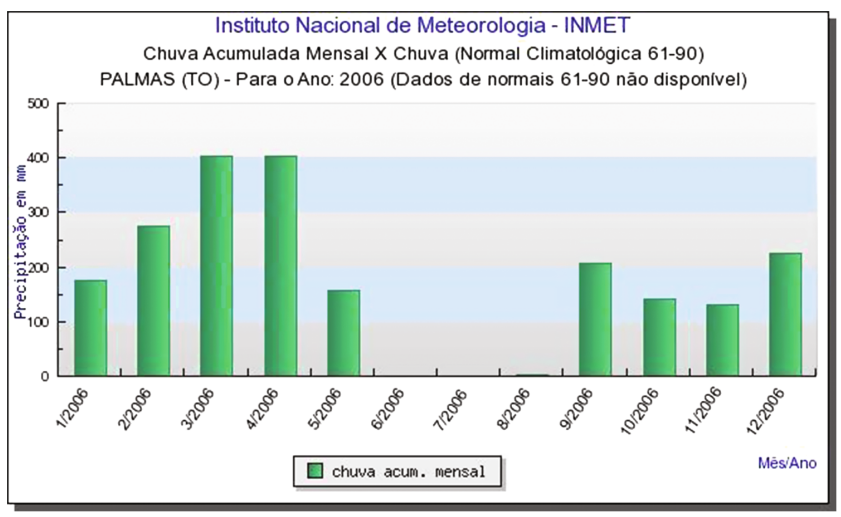

Fig. 23. Accumulated rainfall of 2006 .

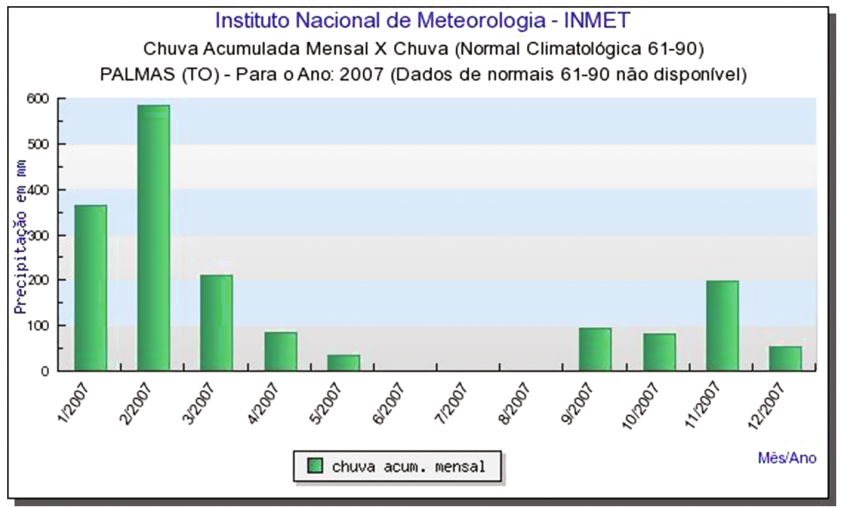

Fig. 24. Accumulated rainfall of 2007. 
Acknowledgments. The Reforsolo Engenharia Ltd., CMT Engineering, Catholic University of Brasilia (UCB), University Center of Brasilia (UniCEUB) and the Institute of Higher Education Plateau with important contributions that made possible the realization of this work.

\section{References}

ABNT/ NBR 7181: Solo - Análise granulométrica

ABNT/NBR 6457: Solo - Amostras de solo - Preparação para ensaios de compactação e ensaios de caracterização

ASTM D3080/D3080M:2011 - Standard Test Method for Direct Shear Test of Soils Under Consolidated Drained Conditions

Geo-slope international: Stability modeling with SLOPE/W, an engineering methodology (2007a)

Geo-slope international: Stress deformation modeling with SIGMA/W, an engineering methodology (2007b)

INMET (Instituto Nacional de Meteorologia). http://www.inmet.gov.br/portal/ 